\title{
¿EXISTE EL DIALECTO ANDALUZ?
}

EL PUNTO DE PARTIDA

En un trabajo reciente, José Mondéjar se ha ocupado de "si el "andaluz" histórico es un dialecto u otra cosa que podemos llamar modalidad o variedad regional del español''. El estudio consta de dos partes perfectamente solidarias: desenmascarar una serie de falacias y hacerlo desde unos presupuestos teóricos. Los razonamientos esgrimidos contra los sembradores de cizaña son de una implacable contundencia, y nadie que crea en eso que llamamos quehacer científico dejará de aceptarlos. En cuanto a los fundamentos teóricos de si el andaluz es o no un dialecto, he tenido que meditar un poco. Porque un problema de terminología puede significar muchas cosas, sobre todo en días en los que, bajo el uso mendaz de las palabras, se quiere desvirtuar los hechos. Razón por la que ya debemos romper el silencio, si somos conscientes de nuestra propia responsabilidad social. Pero hay más, uno debe defender sus ideas científicas cuando se ponen en tela de juicio o cuando son combatidas silenciándolas. He dejado pasar tiempo para escribir sin ninguna urgencia. Además, lo hago desde una lejanía que da un aire pueblerino a todo lo que no es la verdad, con lo que se gana en objetividad. Y, por último, que Mondéjar sea mi amigo entrañable no debe impedir que digamos, ambos, lo que creemos sobre cuestiones de nuestro oficio.

1 "Naturaleza y estatus social de las hablas andaluzas", en MANUel ALVAR (coord.), Lenguas peninsulares y proyección hispánica, Fundación Friedrich Ebert-Instituto de Cooperación Iberoamericana, Madrid, 1986, pp. 143-149. El fragmento que aquí transcribo está en la p. 143. 


\section{LA OBJETIVIDAD DE LOS HECHOS}

Para justificar lo que van a ser sus razonamientos, parte el autor de dos textos míos: uno de 1964 (que le parece bien), y otro de 1961 (que no se lo parece tanto). Pongamos en orden la cronología: cuando escribí el artículo en el homenaje a don Alfonso Reyes $^{2}$ partíamos de un conocimiento de los hechos que había facilitado el 'ALEA; hoy, tantos años después, y sabiendo mucho más de la dialectología española y de la americana, las cosas siguen teniendo el mismo carácter: los rasgos andaluces son más, muchos más de los que aisladamente pueden darse en lo que se llaman hablas meridionales, lo que no es un término justo, o atlánticas, que tampoco lo es ${ }^{3}$. Que un rasgo andaluz como, por ejemplo, la aspiración de la ese se dé en Salamanca, en Ávila o en Toledo ${ }^{4}$, que la neutralización de $l=r$ aparezca - por decir un solo dominio- en Puerto Rico ${ }^{5}$ o que haya abertura de vocal en los plurales en algún sitio del español rioplatense ${ }^{6}$, no creo que quiten fisonomía al andaluz, ni la pierda porque encontremos otros rasgos suyos en canario o en murciano. No creo que ningún aficionado a la dialectología confunda a un hablante de Las Palmas o de Cartagena con otro de Málaga. Sigo creyendo en unas palabras mías que cita el Prof. Mondéjar:

Lo que viene a crear su especial fisonomía [del andaluz] es la enorme cantidad de rasgos que aquí se han dado cita; el grado extremo a que se han llevado todos los procesos, la altura social que

2 "Hacia los conceptos de lengua, dialecto y hablas", NRFH, 15 (1961), 54-59. Lo he recogido en La lengua como libertad, Cultura Hispánica, Madrid, 1982. Citaré por este libro, porque en él agrupo otros trabajos que ahora necesitaré usar. En la p. 145 de su estudio, Mondéjar cita con inexactitud mi título; hay otros errores, como antonomasia por autonomía, que pienso deberán cargarse a la cuenta del impresor.

${ }^{3}$ Véase Gregorio Salvador, "Discordancias dialectales en el español atlántico", en el I Simposio Internacional de Lengua Española (1978), Las Palmas, 1981, pp. 351-362.

${ }^{4}$ Véase Antonio Llorente, Las hablas vivas de Zamora y Salamanca en la actualidad (en la obra que cito en la nota 1, pp. 117-118); Máximo TORREBLANCA, "Estado actual del lleísmo y de la h- aspirada en el noroeste de la provincia de Toledo", RDTP, 30 (1974), 77-89.

${ }^{5}$ Baste recordar el libro clásico de Tomás Navarro, El español en 'Puerto Rico, Universidad de Puerto Rico, Río Piedras, 1948, pp. 76-88.

${ }^{6}$ Washington Vásquez, El fonema /s/. en el español de Uruguay, Montevideo, 1953. 
han alcanzado uno a uno y el conjunto de las manifestaciones lingüísticas.

Y esto caracteriza al andaluz dentro de las demás hablas que proceden - naturalmente- del castellano. Las caracterizaciones en lingüística, y fuera de ella, se hacen "por asociación" de discrepancias, ¿cómo si no?

Por otra parte, Mondéjar dice:

Todas las hablas meridionales conocen, en mayor o menor grado, la aspiración de la -s implosiva, la abertura de la vocal final, la aspiración de las velares sordas, la confusión de $r$ y $l$ en final de sílaba o su pérdida en posición final absoluta, etcétera.

Aquí hay reunidás cosas heterogéneas: no se puede mezclar la aspiración de la $-s$, que es un proceso de la "demolición" de la $s$ implosiva del indoeuropeo ${ }^{7}$, que afecta a muchísimas lenguas y en la nuestra tiene enorme difusión, con la abertura de la vocal final, pues no se ha resuelto del mismo modo la manifestación del plural en rumano y en granadino. Ni en sevillano y granadino, con lo que tendremos otro hecho básico al que me referí hace casi treinta años: "[las Andalucías] que nosotros podamos descubrir carecen por completo de cierta uniformidad o "nivelación» lingüística"' (p. 63) y esto es un rasgo dialectal, porque, si no lo fuera, habría que ir pensando en otras cosas. En sociedades como las nuestras, donde escribir no es difícil, los dialectos sólo sirven para una literatura de escaso valor, pues la creación duradera está en la lengua de cultura ${ }^{8}$. No vale decir que entonces no se trata sino de variedades; la diferenciación es algo sobre lo que voy a escribir y sobre lo que escribiré. Pero no puedo aceptar que "todas las hablas meridionales conocen en mayor o menor grado" unos cuantos fenómenos. Sí, pero vuelvo a mi granadino: ¿ su abertura vocálica es como la de otros sitios? ¿Es el granadino como el panocho, como el jándalo o como el palmero? Me refiero al grado de originalidad. Y quedan cosas que no entran en el informe de mi compañero: nada se dice de la desoclusivización de la $c h$, que obliga a un reajuste fonológico de todo el sistema de las palatales

7 Véase M. Alvar, "Las hablas meridionales de España y su importancia para la lingüística comparada", $R F E, 39$ (1955), 284-313.

${ }^{8}$ Véase mi Lengua y dialecto, cuestión de prestigio, Universidad, Alcalá de Henares (en prensa). 
y, vinculado con él, del de las dentales; nada dice de la pérdida de las implosivas que unido, allí donde se da, al hundimiento del sistema pronominal castellano, fuerza a una reagrupación de las formas verbales, brillantemente estudiadas por Mondéjar ${ }^{9}$, pero que sólo en parte coincide con América (faltan el voseo y formas concurrentes) y está creando una ordenación de los pronombres muy extraña al castellano ${ }^{10}$. Con lo que tendríamos una formación del plural o una neutralización de los signos que nada tiene que ver con la norteña y una estructura del sistema verbal igualmente diferenciada. ¿No es esto "sentido vulgar" del término dialecto? Y añadamos otras discrepancias: leísmo, laísmo y loísmo son desconocidos en Andalucía, mientras que ya están muy firmemente asentados en Castilla; se argüirá que es Castilla la disidente, pero ¿̇habrá o no disidencia cuando el rasgo afecta a León, Extremadura, Castillas, La Mancha? Para mí el mantenimiento etimológico es otro rasgo diferenciador, por más que sea arcaizante, frente al carácter innovador de Andalucía frente a Castilla. Y cuido mucho no decir español para no complicar y enmarañar las cosas. Habría también que hablar de lexicalización de fenómenos fonéticos que, lógicamente, afectan al vocabulario y la originalidad del léxico, por más que no se crea ${ }^{11}$, o tras los trabajos de Julio Fernández-Sevilla y José Andrés de Molina ${ }^{12}$, mal podemos decir que no esté alterada la estructura "lexicosemántica" del castellano, y no hablemos del uso de los pronombres, tan reiterado frente al septentrional, o sintagmas ${ }^{13}$ como no empujéis, nunca más, nada más, vamos ahora mismo, cuanto más... mejor, etc., desconocidos por el castellano bajo las formalizaciones andaluzas y que si los cito aquí es porque están en el 'ALEA, tan poco rico,

${ }^{9}$ El verbo andaluz. Formas y estructuras, C.S.I.C. Instituto Miguel de Cervantes, Madrid, 1970 (Premio Antonio de Nebrija, 1959). Esta importante obra tuvo el valor de anticipar lo que ya se había allegado para el 'ALEA y que se tardó en ordenar, precisamente con la colaboración del autor (t. 6 del Atlas).

${ }^{10}$ 'ALEA, 6, mapas 1821-1833, donde se consignan no pocas anomalías con respecto a la norma común.

11 Publiqué hace mucho un trabajo de conjunto, escrito años antes (en 1959 lo expuse en Río Grande Do Sul): “Estructura del léxico andaluz”, BdFS, 16 (1964), 5-12.

${ }^{12}$ Respectivamente: Formas y estructuras en el léxico agricola andaluz, C.S.I.C., Madrid, 1975; Introducción al estudio del léxico andaluz, Granada, 1971.

${ }^{13}$ Véase Antonio Narbona, "Problemas de sintaxis coloquial andaluza", REL, 16 (1986), 229-275. 
como suelen ser todos los atlas, en problemas de sintaxis ${ }^{14}$. No seré yo quien niegue que esto son variedades, pero habrá que encontrar el registro preciso para poderlas definir. Insistiré en ello.

Volvamos ahora a mi opinión de 1964. El profesor Mondéjar copia un trecho en el que digo:

Las hablas canarias no son un dialecto. Ni uno solo de sus rasgos fonéticos es privativamente suyo, ni su léxico se diferencia de los otros [ ...]. Pertenece a un gran complejo [...] en el que cabrían el extremeño del sur, el andaluz, el murciano $[\ldots]^{15}$.

A la tesis de mi gran amigo le conviene que el andaluz forme bloque con esas hablas meridionales en las que diluiría su originalidad, pero mis ideas son muy precisas, y lo eran hace muchos años. Nada de particular tendría cambiarlas (para bien), pero siento decir que no las he cambiado.

Cuando inventé el $A L E A$ (1952) apenas si sabíamos algo del andaluz; del canario, hasta 1959, poco más que nada. Cuando puse en marcha el ALEICan (1964) ya había publicado tres tomos del $A L E A^{16}$. Es decir, podíamos establecer, desde mi punto de vista, una coordinación de saberes que estaban explícitos en la propia orientación del ALEICan. Para Mondéjar, el decir yo que el andaluz es un dialecto y el canario no, supone "establecer dependencias de estatus que [ ...] parecen no existir" en mi pensamiento. Nada más lejos de la realidad, y para explicarlo recurro al mucho saber de un romanista tan ilustre como Mondéjar ${ }^{17}$. Cuando tratamos de ordenar, recurrimos a los rasgos comunes de unas lenguas; así decimos que el rumano, el rético, el sardo, etc., son lenguas románicas por lo que las agrupa (su base latina); es lo que hice en mi texto de 1964; pero al decir que el fran-

${ }^{14}$ Sobre estas dificultades, véase R. A. Hudson, Sociolinguistics, Cambridge University Press, Cambridge, 1980, p. 46.

${ }^{15}$ Las mutilaciones son mías, pero no atañen a lo que voy a decir. Mi redacción no parece gustarle a mi ilustre amigo y pone el sambenito de (sic) a una referencia para mí muy clara: el antecedente es dialecto y no hablas, cuestión de estilo. Como lo son los estilemas pleonásticos de $l e$ : "la interpretación que le di a este texto" (p. 144), "la existencia de todos y cada uno de los rasgos [...] es lo que le resta individualidad al dialecto" (p. 145).

${ }^{16}$ La obra debiera haberse acabado de imprimir en 1967, de haber seguido con el ritmo que teníamos marcado; si no se hizo fue por la estafa con que nos agració la piedad de un grabador.

17 Dicho brevemente: el canario es andaluz, cf. infra. 
cés es una lengua románica no se me ocurre pensar que no esté bien diferenciada, ni al enumerar las "hablas hispánicas meridionales" se me ocurre negar la fuerte diferenciación del andaluz. Cuando tratamos de caracterizar en lingüística, lo hacemos por lo que es discrepante, original o como queramos llamarlo, y entonces el portugués, el español o el italiano lo son por lo que no se parecen, es decir, por sus peculiaridades; o el andaluz, frente al canario, por las suyas.

Pero esto que es claro, y que no debiera merecer más comentarios, se ha tergiversado, pienso que inconscientemente. En el arranque mismo del estudio están esas palabras de "si el andaluz histórico es un dialecto u otra cosa" (p. 143). ¿Qué quiere decir andaluz histórico? Porque lo que en el trabajo se estudia es el andaluz, como mucho a partir de 1881 , y siempre que se hacen referencias se hacen, tal y como la lógica impone, a situaciones actuales; es decir, se ha mezclado andaluz histórico (hecho de diacronía) con naturaleza y estatus social de hoy (hecho sincrónico) con lo que se han venido a enrevesar cosas que deben estar separadas. $\mathrm{El}$ andaluz histórico es, lisa y llanamente, castellano ${ }^{18}$; el andaluz de hoy no es castellano. Es decir, la "gramática histórica" del andaluz es el castellano; la del castellano, el latín. Y aquí entran las diferencias: el canario no es castellano trasplantado a las Islas y allí evolucionado, sino andaluz, concretamente modalidad lingüística sevillana llevada desde Sevilla (y Jerez y Cádiz) ${ }^{19}$ y evolucionada allí como evolucionó en Andalucía. Es decir, el canario es históricamente andaluz (una modalidad del andaluz) y el andaluz es históricamente castellano. Si Mondéjar no piensa así, estaremos hablando desde galaxias heterogéneas, pero no lo creo: ha tenido un desliz al involucrar la historia. Y, en la historia, estamos totalmente de acuerdo. Nos separa un problema de sincronía. Pienso que ni siquiera esto: una pequeña cuestión de nomenclatura que - lo diré mil veces - mi entrañable y muy querido amigo ha forzado para llevar mis ascuas a sus sardinas, cuando en la realidad tiene toda la razón; en la ciencia, plena autoridad y en la dialéctica, la fuerza de la mandarria blandida por el herrero de Goya.

${ }^{18}$ Porque cuanto sabemos del andaluz como tal no está en los viejos textos que tan pobres son en las manifestaciones dialectales.

${ }_{19}$ Para no extenderme en referencias bibliográficas, véase el cap. 3 "Sevilla y Las Palmas" en mi libro Niveles socioculturales en el habla de Las Palmas de Gran Canaria, Cabildo Insular de Gran Canaria, Las Palmas, 1972, pp. 51-57. 
En el manoseado artículo de 1961 (Mondéjar lo caracteriza como "muy conocido") intenté plantearme la cuestión de qué era lengua, qué dialecto, qué hablas. Dije entonces cuán imprecisa era una terminología que no es lingüística, sino paralingüística ${ }^{20}$. ¿Por qué un sistema se llama lengua y otro dialecto? Para mí, hoy, sencillamente por razones de prestigio. Ahora bien, a lo largo del tiempo los lingüistas han ido exponiendo sus criterios con la pretensión de aclarar las cosas: así historicistas y estructuralistas, así idealistas y positivistas, así geógrafo-lingüistas o sociólogos ${ }^{21}$. Para todos, sin excepción, dialecto es una diferenciación ${ }^{22}$ y ha habido lingüistas que ven la diferencia sólo cuando la lengua originaria ha desaparecido y quedan, únicamente, sus herencias. Otros (entre los que me encuentro) juzgan que no es necesario esperar la muerte de una lengua para que podamos ir viendo sus muchas diferencias. Y entonces surge el problema de la nomenclatura. Después de no poco especular y ver lo que los demás habían dicho, llegué a la conclusión de que dialecto es "un sistema de signos desgajado de una lengua común, viva o desaparecida; normalmente con una concreta limitación geográfica, pero sin una fuerte diferenciación frente a otras de origen común" (p. 62). Para mí, y acabaré ya de referirme a ese artículo tan antiguo, todos estos rasgos se dan en el andaluz. Decir que es un hecho indiscutible que "las hablas andaluzas, respecto del español, no difieren sustancialmente de la lengua histórica, encarnada en cada región con variantes" me parece cerrar los oídos a la realidad. Porque ¿qué es el español?, ¿qué es la lengua histórica? ¿El español es lengua histórica? Creo que así, en montón, las cosas no se entienden. Intentaré decir lo que pienso:

Español es el suprasistema abarcador de todas las realizaciones de nuestra lengua. O dicho técnicamente: la lengua abstracta que todos aceptamos, que tiene virtualidad en la lengua literaria escrita y que ninguno habla. Es el sistema considerado fuera del

${ }^{20}$ Por eso hacía muy bien Hugo Schuchardt para no animar ni desanimar a sus amigos de Sevilla. Los problemas son muchos y enrevesados. Y si se quiere aducir la suprema autoridad, copiaría un texto: "il est difficile de dire en quoi consiste la différence entre une langue et un dialecte" (FERDINAND DE SAussure, Cours de linguistique générale, éd. critique préparée par Tullio de Mauro, Payot, Paris, 1972, p. 278).

${ }^{21}$ Cf. "La dialectología" (1968), incluida en La lengua como libertad.

22 Véase el cap. 8 de J. B. PRIDE, The social meaning of language, Oxford University Press, London, pp. 60-69, donde se analizan las diferencias entre las lenguas y los dialectos. 
individuo. Pero esta abstracción se realiza en millones de actos comunicativos (la parole) que están trabados por dos órdenes d $\epsilon$ fuerzas, las geográficas y las sociales. De ahí las variedades geográficas (o dialectos tradicionales) y las verticales (o sociolectos)

¿A qué lengua histórica se refiere el andaluz? ¿Al español que se aduce? Si esto es así la formulación es falsa, porque la lengué histórica a la que se debe referir el andaluz no es el español (ine. xistente en el siglo XIII o en el siglo Xv), sino al castellano. Sólc después, los andaluces han ayudado a conformar - ¡y de qué modo! - la unidad de sistema de sistemas que es el español. Por tan to decir que el andaluz no "difiere sustancialmente" del españo es erróneo históricamente y relativo, porque hay que saber que se quiere decir con sustancialmente. En cuanto a las discrepancia: del andaluz con respecto del castellano me parecen de cierta enti dad. Y muchísimas más si pensamos en un "castellano históri co", porque, y estoy totalmente de acuerdo con Mondéjar, "e castellano de Castilla puede ser tan variedad o si se quiere tar dialectal como el andaluz respecto del español"' (p. 146).

Si sustancialmente quiere decir que las discrepancias del anda luz son "pocas" fonológicamente y "bastantes" fonéticamente tendremos que dar contenido objetivo a poco y bastante. Dependt de lo que queramos decir y depende de lo que entendamos po: fonética y por fonología. Porque si es poco el funcionamiento fo nológico de $h$ y $\emptyset$, totalmente distinto del que tiene la jota er castellano ${ }^{23}$, el seseo o el ceceo ${ }^{24}$, el yeísmo y la alteración del sis tema de palatales, la desoclusivización de la $c h$, el reajuste de la dentales, etc., no sé cuál será el valor de mucho $^{25}$. Para mí, pues el andaluz está suficientemente diferenciado ${ }^{26}$. Desde luego sı puede enfrentar a ese español escrito por Alberti, por Lorca o po Pemán, como se puede enfrentar el castellano oral a las obras dı Delibes o el aragonés (aunque menos) a las de Sender. Lo qur es falso, y políticamente embaucador, es negar su dependenci: de lo que Mondéjar llama “español común”. Y en adelante sigı

23 "Sevilla, macrocosmos lingüístico", 'EFL, pp. 13-42. Está mal expre sado decir que en las hablas meridionales conocen "la aspiración de las vela res sordas" (p. 145); no conocen, son, puesto que no proceden de jota.

24 "A vueltas con el seseo y el ceceo", Rom, 5 (1972), 41-57.

${ }^{25} \mathrm{Y}$ no se debe olvidar lo que es la norma regional, que hará desdeñabl en un sitio lo que es aceptado, y hasta universal, en otro (véase "La norm: lingüística", en 'La lengua como libertad, pp. 43-44).

${ }_{26}$ Véase A. LLORENTE, "Fonética y fonología andaluzas", RFE, 4. (1962), 227-240. 
en todo de acuerdo con él. Lo que ocurre es que todas las diferencias que llama variedades para mí son variedades con más valores (por supuesto, no el de la escisión ni la separación políticas). Porque si nos atenemos a lo que Mondéjar quiere significar como dialecto (pero no lo dice) parece que nuestra lengua no los tiene. $O$, si acaso, sólo lo serán los históricos. Volveríamos a estar en el principio: ¿qué grado de diferencia había entre leonés, castellano y aragonés en el siglo XII? ¿Por qué llamamos lengua al castellano y dialecto al leonés? Argumentando con sus mismos razonamientos: hay una lengua, el español común, y unas variedades (el castellano de Castilla, el andaluz, el aragonés actual, el leonés de hoy, el panocho, el chinato, etc.). Conforme, pero, otra pregunta nada retórica ¿ ¿son diferencias del mismo grado las del habla de $\mathrm{Za}$ mora o Salamanca que las que se dan en Málaga? Y quedan otras causas históricas ya apuntadas: la dependencia que tienen del andaluz tantas y tantas modalidades del español actual (no sólo en la Península y en las Islas). Precisamente, diferencias e historia me hacen ver el andaluz como un dialecto y no aceptar que me digan que la "manera de hablar" una lengua es -así, sin más"el sentido vulgar del término [dialecto], no el técnico"' (p. 145), pues buen cuidado he tenido siempre en no confundir "la com" prensión de un habla y el metalenguaje de una ciencia"'27.

\section{ACERCA de Un TEXTo TeÓRICO}

Precisamente, la referencia última que he hecho al trabajo de Mondéjar encierra en el original un hoy subrayado para indicar qué se considera científico y qué no por estas calendas, y el autor aduce el mucho peso que científicamente posee el Prof. Coseriu ${ }^{28}$. Pero aducir una autoridad puede tener sus riesgos, como nuestro autor señalaba al comenzar su trabajo. Por eso hemos de aumentar nuestra cautela si buscamos el amparo del sabio cuyo magisterio reconocemos, y para mí, resulta sorprendente la utilización de tal estudio. Justamente porque dice todo lo contrario de lo que se pretende.

Como es lógico, Eugenio Coseriu señala la dificultad de sepa-

27 "Lengua, dialecto y otras cuestiones conexas", en La lengua como liber. tad, p. 66 .

${ }^{28}$ E. Coseriu, "Los conceptos de "dialecto", "nivel" y "estilo de lengua" y el sentido propio de la dialectología", LEA, 3 (1981), 1-32. 
rar los conceptos de lengua y dialecto, pero intentando aclarar las cosas me limitaré a copiar unos cuantos párrafos del artículo mencionado:

1. "Entre dialecto y lengua no hay diferencia de concepto o "sustancial»" (p. 5), según hemos dicho cuando nos ocupamos del tema.

2. "El término dialecto - contrariamente a una opinión muy difundida - no significa otra cosa que el término lengua. Pero, si todo "dialecto» es una lengua, no toda "lengua» es un dialecto" (p. 5). No me extiendo: es lo que para mí resulta claro desde hace muchos años. El castellano es una lengua y tiene sus dialectos; éstos - evidentemente- no son lenguas.

3. "Un "dialecto", sin dejar de ser intrínsecamente una "lengua", se considera como subordinado a otra "lengua" de orden superior' (p. 6). En mis análisis llamo a esta superioridad prestigio.

4. "El término dialecto, en cuanto opuesto a lengua, designa una lengua menor distinguida dentro de (o incluida en) una lengua mayor, que es, justamente, una lengua histórica"' (p. 6). Argumento evidente: el castellano es dialecto del latín; las "variantes" del castellano son sus dialectos.

5. "Una lengua histórica — salvo casos especiales- no es un modo de hablar único, sino una "familia" histórica de modos de hablar afines e interdependientes, y los dialectos son miembros de esta familia o constituyen familias menores, pero dentro de la familia mayor" (id.). Claro que si las diferencias fueran tan grandes habrían nacido otras lenguas bien diferenciadas (francés, italiano, portugués frente al latín), lo que no ocurre con lo que llamamos dialecto, ni mucho menos, con las hablas locales.

6. "Así, el español de América es, fundamentalmente un dialecto [...] de la lengua española común (es decir, del castellano en cuanto lengua común); y lo mismo cabe decir del andaluz, del canario y hasta del judeo-español' (p. 14). Acepto y preciso: el canario no es sino andaluz, con ciertos componentes léxicos (muchos portugueses y pocos prehispánicos); el judeo-español es una koiné con diversos integrantes en cada asentamiento de la diáspora.

Justamente a estas situaciones se llega también por otros caminos; lo que es lógico, si las formulaciones son exactas. Coseriu - sin embargo, ¿cómo iba a creerlo? - no dice qué altura debe alcanzar el termómetro para decir esto es variante y aquello dialecto. No puede decirlo porque se mueve en un plano teórico en el 
que - bien lo sabemos todos- no hay diferencias entre lengua y dialecto; el nudo de la realidad práctica es el que ahora nos afecta y entonces resulta que dialecto es "un modo de hablar subordinado a una lengua histórica, delimitado en el espacio" 29 . Retomo la cuestión: castellano, lengua histórica con respecto al andaluz, pues esa lengua está "por encima de la variedad dialectal". Nadie ha negado que dialecto y variedad sean términos válidos; lo que ocurre es que establecemos una jerarquización que parece evidente: el andaluz es un dialecto del castellano y en ese dialecto hay multitud de variedades (sevillanas, cordobesas, almerienses y, también, (anarias) ${ }^{30}$.

\section{SObRe SOCIOLINGÜÍSTICA}

En 1979 publiqué el artículo "Lengua, dialecto y otras cuestiones conexas"'31. Traté de hacer ver cuán inoperantes eran en Rusia las cosas que como marxistas se nos querían servir por estos andurriales. Hoy las cosas me parecen más claras todavía: los poderosos exportan a los débiles los productos tarados que no les sirven en casa ${ }^{32}$, mientras ellos tratan de fortalecerse, también en lingüística. Por ejemplo:

The Russification polices of the Tsars were deliberate attempts to use the Russian language as the "cement of empire". Although there were a few who called for the use of other national languages in school, no real change occurred until after the Revolution ${ }^{33}$.

${ }^{29}$ Según ibid., p. 12, nota 13

30 Valga para acabar otro texto de CoseriU: "El andaluz de Sevilla, si se considera absolutamente [... ] será «la lengua popular de Sevilla». Y si se considera desde el punto de vista de su estatus histórico será: «el dialecto de Sevilla», si se deslinda directamente dentro de la lengua histórica española; «el dialecto de Sevilla", si se deslinda dentro del "dialecto andaluz"; y "el subsubdialecto de Sevilla", si se deslinda dentro del andaluz y éste se considera, a su vez, en relación con el "dialecto castellano", como "subdialecto" del mismo" (op. cit., p. 11).

${ }^{31} L E A, 1$ (1979), 5-29, ahora en La lengua como libertad. Véase también "La norma lingüística" en ibid.

32 Trato de esto en "Planificaciones y manipulaciones lingüísticas", en el libro colectivo Lengua y sociedad (en prensa).

${ }^{33}$ Con muchísimas referencias bibliográficas que apoyan el aserto, en John Edwards, Language, society and identity, Oxford, 1985, p. 180. 
Como el trabajo de Mondéjar coincide con el mío en no pocas afirmaciones, e incluso referencias, por haber ido ambos a las fuentes de primera mano, no voy a hacer sino suscribir lo que él dice. Me gustaría apoyarle en algún punto: el complejo de inferioridad de los andaluces lo tienen también los aragoneses, los canarios, los púertorriqueños (¿quiénes no?) pero no por ser lo que son, sino por ser incultos ${ }^{34}$. Si se les diera la educación a que tienen derecho, el complejo de inferioridad desaparecería, porque la tal inferioridad no existe. Yo quisiera ampararme en juicios ajenos no para tener más razón, sino para que la mía esté amparada por quien ni de lejos ha saludado nuestros problemas. Hablar de una manera, si detrás de ella está la conciencia del saber, no le parece vituperable a quien la utiliza. Mondéjar lo ha dicho y bien; por mi parte añadiría que los sociolingüistas han llegado a la conclusión de que el dialecto viene a ser el conjunto de "variedades según el usuario" y dentro de él están los registros, que son las "variedades según el uso" "35, con lo que resulta que el dialecto muestra lo que uno es y el registro lo que hace. Por tanto, el dialecto andaluz (de ahora en adelante le llamará dialecto) presenta todas esas variedades que hemos señalado y la "complejidad" de los andaluces está en la inadecuada utilización de su dialecto. Lo mismo que en todas partes. Más aún, contra ella está la conciencia social de cómo se habla, que no es - precisamente - sentido de inferioridad, sino porque la altura social del dialecto afecta a todos $^{36}$, lo que podría hacer pensar en una situación diglósica, tal y como propone Fasold:

That diglossic community be defimed as a social unit which shares the same High and Low varieties. Each speech community must share not only the same $\mathrm{H}$, but the same $\mathrm{L}$ as well ${ }^{37}$.

34 Véase "Actitud del hablante y sociolingüística" [1977] en mi libro Hombre, etnia, estado, Madrid, 1986, y las muchas referencias que a la cuestión se pueden entresacar en el índice de la obra (s.v. español).

${ }^{35}$ Hay no poca bibliografía recogida por R. A. Hudson, op. cit., pp. 48-49. Claro que hay mucho que hablar sobre ello, véase el trabajo de CoseRIU que he comentado y las páginas de José JOAQUín MONTES, "Dialectología y sociolingüística: algunas ideas sobre sus interrelaciones", $L E A, 8$ (1986), 133-141.

${ }^{36}$ Lo escribí en 1961 cuando hablé de "la altura social" de sus rasgos (p. 64)

37 The sociolinguistics of society, Oxford, 1984 [reimpresión 1985], p. 44. Hay que leer también las pp. 34-38. Es útil considerar el estudio de Einar Haugen, 
Las atenuaciones que hay que formular no son pocas y a ellas ya me referí. Pero el "comportamiento institucionalizado" es - lo he recogido alguna vez - "el objeto de la moral interna de los sentimientos" 38 y, en definitiva, el "ruralismo y la expresión mazorral" de quienes no deberían utilizar semejantes registros no es otra cosa que la pobre visión de la vida que los tales poseen ${ }^{39}$, y resulta antidemocrático querer imponer la barbarie por el solo hecho de ser local o inculta ${ }^{40}$.

Y esto me obliga a perfilar algo que escribí en 1976 y que he reeditado en $1986^{41}$. El estudio del mapa 5 del $A L E A$ me hizo ver con claridad cuál era la conciencia lingüística de los andaluces: hay un ideal mejor de lengua que es el castellano, aunque no siempre ni colectivamente, pero también

una fuerte identificación con su dialecto [ ...]. Y es que unas hablas como éstas, muy diferenciadas de la lengua común, sirven para acentuar el sentido dialectal de las gentes que las emplean; más aún crean una autoafirmación de personalidad que les hace descuidar todo aquello que les es dispar, y eso desde el catedrático de Universidad hasta el último bracero, con lo que resulta que el dialecto tiene un prestigio social que difícilmente alcanza en ningún sitio del país, y es que en Andalucía se trata de una conciencia colectiva íntimamente sentida (p. 18).

A continuación de estas palabras ponía otras que son verdad e historia, pero ahora utilizadas al servicio de algunos de los nuevos mandatarios; entonces escribí que tal conciencia colectiva no era "activada o motivada por idealismos de clases dirigentes" 42 . Leyendo a Mondéjar tal vez haya que atenuar lo de idealismo y, por supuesto, lo de clases dirigentes, so pena que como tales tengamos

\footnotetext{
"Bilingualism, language contact, and inmigrant languages in the United States: A research report 1956-1970", en la obra coordinada por JosHUA A. Fishman, Societal multilingualism, La Haya-Paris-New York, 1978, pp. 1-111.

${ }^{38}$ BERnARD BARBER, Social Stratification. A comparative analysis of structure and process, New York, 1957, p. 353.

${ }^{39}$ Véase "La norma lingüística", p. 39. Léase también lo que digo en la p. 42 :

40 Ibidem, pp. 44-45. Véase mi estudio "Fonética, fonología y ortografía" [1979], en La lengua como libertad, pp. 241-242, que también hay furores ortográficos desatados por nuestras ciudades.

41 "Actitud del hablante y sociolingüística", ahora en Hombre, etnia, esta-

do. Cf. la explicación bibliográfica de la p. 10 .

${ }^{42}$ MondÉJAR, "Naturaleza y estatus social...", p. 149.
} 
a ciertas mentes calenturientas de las que más vale no acordarse.

Que el andaluz así, en bloque, no existe como le n g u a es evidente, porque si existiera sería algo distinto del español, y eso es una falsedad que no merece la pena discutir. Sí hay una conciencia regional - hasta donde llega lo de conciencia regional, que no son las fronteras administrativas de Andalucía - de tipo diferenciador: de Despeñaperros para abajo es una cosa, a la que los andaluces llaman España, y de Despeñaperros arriba, otra, a la que despectivamente dicen el Norte. Pero no nos dejemos ganar por los exabruptos: aquí acaban las cosas y la lingüística tiene muy otras exigencias.

\section{GONCLusión}

"Nosotros no tenemos más que una lengua que es la española", las variedades orales pueden mostrar diferencias geográficas o sociales. Aquéllas adoptan diversos registros de lengua; éstas se borran con la educación (no con la zapa demagógica) de las clases menos instruidas. No hacer esto es volver a posiciones retrógradas $^{43}$ y a la folklorización cultural ${ }^{44}$.

Manuel Alvar State University of New York, Albany

43 Véase John Edwards, op. cit., pp. 101-107.

${ }^{44} \mathrm{Cf}$. Planificaciones y manipulaciones lingüisticas (en prensa). 